\title{
Assessment of Knowledge, Attitude, and Practice of Health-Care Workers Towards Hepatitis B Virus Prevention in Kabul, Afghanistan
}

\author{
Rohullah Roien (1) \\ Sayed Hamid Mousavi' \\ Akihiko Ozaki $\mathbb{D}^{2,3}$ \\ Sayed Abulqasem Baqeri \\ Sayed Mohammad Reza \\ Hosseini $\mathbb{D}^{\prime}$ \\ Shoaib Ahmad ${ }^{4}$ \\ Sunil Shrestha $\mathbb{D}^{5,6}$ \\ 'Medical Research Centre, Kateb \\ University, Kabul, Afghanistan; \\ ${ }^{2}$ Department of Breast Surgery, Jyoban \\ Hospital of Tokiwa Foundation, Iwaki, \\ Fukushima, Japan; ${ }^{3}$ Medical Governance \\ Research Institute, Tokyo, Japan; \\ ${ }^{4}$ Department of Pediatrics, District Head \\ Quarters Teaching Hospital, Faisalabad, \\ Pakistan; ${ }^{5}$ Department of Pharmaceutical \\ and Health Service Research, Nepal \\ Health Research and Innovation \\ Foundation, Lalitpur, Province Bagmati, \\ Nepal; ${ }^{6}$ Nobel College Faculty of Health \\ Sciences, Pokhara University, Kathmandu, \\ Province Bagmati, Nepal
}

Correspondence: Rohullah Roien; Sayed Hamid Mousavi

Email Rohullahroien@kateb.edu.af;

Dr.mousavi@kateb.edu.af
Background: Hepatitis B virus (HBV) infection is a serious public health issue around the world. Health care workers (HCWs) are at high risk of HBV infection because they have direct contact with HBV infected blood and body fluids in their work.

Objective: The purpose of this study was to evaluate the knowledge, attitude, and practice (KAP) of HCWs towards hepatitis B infection in Kabul, Afghanistan.

Methods: This cross-sectional study was conducted on $502 \mathrm{HCWs,} \mathrm{between}$ November 2018 and January 2019 by a simple random sampling method. The data was collected through a self-administered structured questionnaire. Using this questionnaire, demographic characteristics and KAP of HCWs was assessed. In addition, descriptive and inferential analyses was conducted on the collected data using SPSS 16 (SPSS Inc., Chicago, IL, USA).

Results: The overall KAP scores of HCWs were found to be $86.58 \%, 34.73 \%$, and $61.22 \%$, respectively. Most of the participants correctly recognized the HBV infection. Among the participants, only $77.45 \%$ had undergone screening for $\mathrm{HBV}$, and $56.37 \%$ had received $\mathrm{HBV}$ vaccine $(\mathrm{p}<0.0001)$. Moreover, only $6.77 \%$ had completed the three doses of vaccination for HBV. Among the HCWs, the group with higher education level had better knowledge than the group with lower education level. However, the attitude of most of the participants towards HBV prevention was found to be inadequate $(53.98 \%)$.

Conclusion: This study shows that HCWs in Kabul, Afghanistan are at high risk of HBV infection due to low vaccination coverage and inadequate infection control. Therefore, we strongly encourage providing an accessible and compulsory vaccination program for all HCWs to improve their attitude and awareness towards HBV infection and to achieve effective infection control.

Keywords: hepatitis, hepatitis B virus, Kabul, health care worker

\section{Introduction}

Hepatitis B is an infectious disease caused by a virus called hepatitis B virus (HBV). The inflammation associated with a hepatitis $\mathrm{B}$ infection can lead to complications such as liver cirrhosis, liver failure, liver cancer and death. It is a serious public health issue worldwide, causing severe mortality and morbidity. HBV can be transmitted by blood and blood products, bodily fluids during sexual intercourse, pregnancy and childbirth, and exposure to medical equipment. The estimated prevalence of $\mathrm{HBsAg}$, the surface antigen of $\mathrm{HBV}$, in the global population is $3.9 \%$, and approximately 296 million people are chronically infected with 
HBV, with 1.5 million new infections annually. In 2019, this infection caused 820,000 deaths from complications such as cirrhosis and hepatocellular carcinoma. ${ }^{1}$

Health care workers (HCWs) are at high risk of HBV infection because they directly contact HBV infected blood and body fluids in their work. HBV is infected incidentally by direct contact with HBV infected blood or body fluids through the skin or mucosal membranes. ${ }^{2-}$ ${ }^{4}$ Compared to the general population, HBV infection rate among HCWs is four times higher., ${ }^{4,5}$ Among 35 million HCWs worldwide, about 3 million are exposed to pathogens through blood every year. ${ }^{6}$ Approximately $5.9 \%$ of them are infected with HBV every year. ${ }^{5}$ The HBV infection rate among HCWs varies from $0.8 \%$ to $74.4 \%$, depending on the region where they work. $^{7}$ The risk of HBV infection at work for HWCs is higher in developing countries due to the high prevalence of HBV in the general population, the poor health-care environment, ${ }^{8-10}$ and the lack of awareness and proper infection control measures against blood-borne infections. ${ }^{11}$

$\mathrm{HBV}$ vaccination is the cornerstone of $\mathrm{HBV}$ infection control and has been very effective, safe, and provides lifelong protection. ${ }^{7}$ Other effective approaches include improving health education for both infected and noninfected high-risk groups, implementing standard precautions such as regular personal hygiene, proper use of gloves and other equipment, adequate sterilization of medical equipment, and proper disposal of body fluids and other clinical waste in medical facilities. ${ }^{12}$ In addition, precautions with the HBV vaccine and/or hepatitis B immune globulin (HBIG) can prevent infection in the first 24 hours after exposure. ${ }^{13}$ Therefore, it is suggested that all HCWs should be vaccinated against HBV infection as part of occupational infection control measures. Despite this recommendation, vaccination coverage of HCWs, especially in developing countries, is still very low and this is a challenge for the country and/or for HBV patients. WHO reports that HBV vaccination coverage in low- and middle-income countries (LMIC) is only $18-39 \%$, while it is reported to be $67-79 \%$ in high-income countries. ${ }^{7}$

In Afghanistan, information on $\mathrm{HBV}$ is limited. Limited study reported the prevalence of $\mathrm{HBV}$ in Afghanistan as $1.53 \%$ in the obstetric population in Kabul hospitals, $6.54 \%$ in female sex workers (FSWs), $6.15 \%$ among injectable drug users, and $3.9 \%$ in blood donors. ${ }^{14}$ However, there is no data available on the prevalence, vaccination status, knowledge, or attitudes of HWCs regarding HBV infection in Afghanistan. On the other hand, HCWs who have adequate knowledge of HBV infection and are well trained play important roles in implementing HBV infection control programs. Lack of knowledge and unfavorable attitudes of HCWs have been suggested to be obstacles in providing health education and controlling HBV infection. Transfusions of blood and blood products, needle sharing by intravenous drug users, sexual activity, etc were the main risk factors for HBV infection in Afghanistan. ${ }^{14}$ The purpose of this study was to assess HCWs' knowledge, attitudes, and practices regarding HBV infection in Afghanistan.

\section{Method}

\section{Study Design and Study Site}

This institution-based, cross-sectional study was conducted between November 2018 and January 2019 to assess HCWs' knowledge, attitude, and practice (KAP) towards HBV infection. The study was conducted among HCWs, including doctors, nurses, midwives, medical technologists, dentists, and anesthetists working at 12 public and private hospitals in four different zones in Kabul (South, East, West, and North) during the research period. Kabul is the capital and largest city of Afghanistan, with a population of approximately 7 million. Five hundred two participants were selected for the study by simple random sampling method.

\section{Study Population}

The participants of the study were HCWs, including doctors, nurses, midwives, medical technologists, dentists, and anesthetists working in public and private hospitals during the research period. HCWs include people who work formally and contractually in public and private hospitals in specialized departments, including internal medicine, surgery, obstetrics, dentistry, pediatrics, orthopedics, medical laboratory, midwifery, nursing, etc. HCWs were chosen based on previous studies indicating a high risk of HBV infection among HCWs in developing countries because of a high prevalence of HBV among the general population, poor condition of health care settings, ${ }^{12,13,15}$ lack of awareness and appropriate precautions against bloodborne infections. ${ }^{14} \mathrm{HCWs}$ play an important role in providing medical services in hospitals and need adequate knowledge and a positive attitude towards HBV infection control to take the necessary precautions to prevent infection from spreading. 


\section{Inclusion Criteria}

- Public and private hospitals, registered in the Ministry of Public Health and located in Kabul City, Afghanistan.

- HCWs working at public and private hospitals, willing to participate in the study.

\section{Exclusion Criteria}

- HCWs not willing to participate in the study.

- Public and private clinics and health centers.

- HCWs who were absent during the research period or whose questionnaires were incomplete.

\section{Sampling Method and Technique}

Samples were collected by using a multi-stage sampling method. The city of Kabul was divided into four zones (East, West, North, and West) and 22 districts (municipal areas). North zone includes 2, 4, 9, 10, 11, 15 and 17 districts. South zone includes 1, 7, 8, 20, and 22 districts. The East zone includes 3, 5, 6, 13, and 14 districts, and the West zone includes 12, 16, 18, 19, and 21 districts. Out of 22 districts with a total of about 200 hospitals, 4, 13, 18, and 22 districts were selected, and in each district, 3 hospitals were selected by simple random sampling method. We asked for a list of HCWs from each hospital and selected the required number of participants from the list using a simple random sampling method. We coordinated with hospital officials in advance and invited 35 to $55 \mathrm{HCWs}$ to participate in this study.

In a communication with the invited HCWs, trained members of the research team briefly introduced the objectives of the study to them. Specifically, the research members informed the HCWs that each questionnaire would be filled out without personal identification and analyzed for academic publication, and that filling in the questionnaire would be considered that they agreed to participate in the study. Then, the research members distributed it to the health workers who agreed to participate in the study. Privacy and confidentiality were maintained throughout the study period.

\section{Variables}

\section{Independent Variables}

The independent variables in this study are the sociodemographic characteristics of $\mathrm{HCWs}$, which include their age, gender, and occupation.

\section{Outcome Variables}

Knowledge, attitude and practice (KAP) of HCWs are dependent variables. According to previous similar study, KAP was used as the dependent variable to obtain the relationship between the independent and dependent variables, and demographic characteristics were used as the independent variables. ${ }^{16}$

\section{Data Collection Tool}

We collected data by using a standardized questionnaire taken from a previous study. ${ }^{16}$ We translated this questionnaire into Dari and used it with some minor changes. The questionnaire was reviewed and validated after improvement and translation. These questionnaires were pre-tested on 55 health workers who were excluded from the main study to assess their language, fluency, and understanding of the questions. After the pre-test, the questionnaires were adjusted accordingly to achieve the desired goal of the study. The questionnaire contains 24 questions to assess HCWs' knowledge, attitudes, and practices towards HBV infection. The questionnaire consisted of four parts: the first part includes socio-demographic features, the second part (12 questions) aims to assess knowledge of HCWs towards infection and prevention of $\mathrm{HBV}$, the third part (6 questions) deals with assessing attitudes towards the disease and prevention and the fourth part (6 questions) includes questions regarding practices towards $\mathrm{HBV}$ infection control.

\section{Data Collection Process Scoring System}

Participants who answered $70 \%$ or higher of the knowledge questions correctly were considered good knowledge, while those who answered less than $70 \%$ were considered to have poor knowledge. Participants who answered $70 \%$ or higher of the attitudes questions correctly were considered to have favorable attitudes, while those who answered less than $70 \%$ were considered to have unfavorable attitudes. Participants who answered $70 \%$ or higher of the practices questions correctly were considered good practices, while those who answered less than $70 \%$ were considered to have malpractices.

\section{Data Management and Analysis}

Data management, processing and analysis were done by using statistical package for social sciences (SPSS) version 16 (SPSS Inc., Chicago, IL, USA). Data were analyzed for descriptive and inferential statistics. Descriptive analysis 
was performed using frequencies, percentages and mean \pm standard was presented in the form of text, figures, and tables.

\section{Results}

Six hundred questionnaires were distributed, of which 502 (83.6\% response rate) were returned and analyzed. Table 1 shows the overall characteristics of the study participants. Among the total HCWs, 257 (51.19\%) were female, and 245 (48.8\%) were male. Mean $\pm \mathrm{SD}$ age was $38.5 \pm 19.5$ years (range 19 to 58 years). Of the HCWs, 109 (21.71\%) were medical doctors, $107(21.31 \%)$ were midwives, 103 $(20.51 \%)$ were nurses, 92 (18.37\%) were medical technologists, $78(15.53 \%)$ were dentists, and $13(2.58 \%)$ were anesthetists. 247 participants $(49.20 \%)$ were between the ages of 18-24, and 152 (30.27\%) were between 25-29. 223 $(44.42 \%)$ of the participants had a bachelor's or higher degree.

\section{Level of Knowledge on HBV}

The knowledge of HCWs towards HBV infection is summarized in Table 2.

The overall knowledge of HCWs was $86.58 \%$, and $92.23 \%$ of the participants had good knowledge of HBV. Most of the participants were aware that HBV

Table I Socio Demographic Characteristics of the Study Participants

\begin{tabular}{|l|l|}
\hline Variables & N (\%) \\
\hline Gender & $245(48.8)$ \\
Female & $257(5 \mathrm{I} .19)$ \\
\hline Age & \\
I8-24 & $247(49.20)$ \\
$25-29$ & $152(30.27)$ \\
$30-34$ & $40(7.96)$ \\
$35-39$ & $36(7.17)$ \\
$>40$ & $27(5.37)$ \\
\hline Education level & \\
Master's degree & $20(3.98)$ \\
Bachelor degree & $203(40.43)$ \\
Certification degree & $279(55.57)$ \\
\hline Professions & \\
Medical doctors (MD) & $109(21.7 \mathrm{I})$ \\
Midwives & $107(2 \mathrm{I} .3 \mathrm{I})$ \\
Nurses & $103(20.5 \mathrm{I})$ \\
Medical Technologists & $92(18.37)$ \\
Dentists & $78(15.53)$ \\
Anesthetist & $13(2.58)$ \\
\hline
\end{tabular}

could be infected by unsterile syringes, needles, and surgical instruments $(92.43 \%)$, by contaminated blood and body fluids (94.42\%), by contact with open wounds and cuts $(94.22 \%)$, by unsafe sex (89.64\%), and by mother-to-child transmission (88.44\%). Up to $91.83 \%$ of the participants were aware of the HBV vaccine and knew that the vaccine could prevent HBV infection. Midwives (96.26\%), medical technologists $(92.39 \%)$, and medical doctors (91.74\%) correctly identified unsafe sex as a route of infection for HBV, while anesthetists (76.92\%), nurses (82.52\%), and dentists $(85.89 \%)$ had the lowest level of this knowledge. Only $69.23 \%$ of anesthetists and $89.74 \%$ of dentists identified unsterile syringes, needles, and surgical instruments as a route of $\mathrm{HBV}$ infection. $76.92 \%$ of the anesthetists and $89.74 \%$ of the dentists correctly answered that HBV could be infected by contaminated blood or body fluids. Only $56.77 \%$ of the total participants were aware of post-exposure prophylaxis for HBV. This knowledge was highest among dentists (66.66\%) and lowest among medical technologists $(46.73 \%) .82 .86 \%$ of the participants answered that HBV is treatable This knowledge was highest among dentists $(91.02 \%)$ and the lowest among midwives $(73.83 \%) .79 .88 \%$ of the participants answered that HBV could not be infected by casual contact such as handshaking. This knowledge was highest among anesthetists $(84.61 \%)$ and lowest among midwives $(77.57 \%) .88 .24 \%$ of the participants answered that HBV can cause liver cancer.

The results of multivariable analysis of poor knowledge and attitudes towards hepatitis B prevention among HCWs are shown in Table 3.

Of the 12 questions on knowledge, medical doctors had the highest percentage of correct answers $(87.46 \%)$, followed by midwives $(87.07 \%)$. Anesthetists had the lowest percentage of correct answers (77.56\%). Based on profession, $97.20 \%$ of midwives, $96.12 \%$ of nurses, and $90.83 \%$ of medical doctors had a good knowledge of $\mathrm{HBV}$ infection. However, $15.38 \%$ of anesthetists, $12.82 \%$ of dentists, and $10.86 \%$ of medical technologists were found to have poor knowledge about HBV infection. Among the HCWs, the group with higher education level had better knowledge than the group with lower education levels $(\mathrm{p}<0.0001)$. In addition, women showed a good level of knowledge compared to men $(p=0.022)$. The level of knowledge also varies according to age, as shown in Table 3 of the 
Table 2 Percentage of Participants with Correct Responses to Knowledge Questions by Profession

\begin{tabular}{|c|c|c|c|c|c|c|c|}
\hline Knowledge Questions & $\begin{array}{l}\text { MD } \\
(n=109) \% \\
\text { of } \\
\text { Correct } \\
\text { Answer }\end{array}$ & $\begin{array}{l}\text { Midwives } \\
(n=107) \% \\
\text { of Correct } \\
\text { Answer }\end{array}$ & $\begin{array}{l}\text { Nurses } \\
(n=103) \% \\
\text { of Correct } \\
\text { Answer }\end{array}$ & $\begin{array}{l}\text { Medical } \\
\text { Technologists } \\
(n=92) \% \text { of } \\
\text { Correct Answer }\end{array}$ & $\begin{array}{l}\text { Dentists } \\
(n=78) \% \text { of } \\
\text { Correct } \\
\text { Answer }\end{array}$ & $\begin{array}{l}\text { Anesthetist } \\
(n-13) \% \text { of } \\
\text { Correct } \\
\text { Answer }\end{array}$ & $\begin{array}{l}\text { Total } \\
(n=502) \% \\
\text { of Correct } \\
\text { Answer }\end{array}$ \\
\hline HBV causes liver cancer & $92(84.40)$ & $96(89.7 I)$ & $95(92.23)$ & $80(86.95)$ & $68(87.17)$ & $12(92.30)$ & $443(88.24)$ \\
\hline $\begin{array}{l}\text { HBV carriers can transmit } \\
\text { the infection }\end{array}$ & $92(84.40)$ & $97(90.65)$ & $85(82.52)$ & $79(85.86)$ & $66(84.6 I)$ & II (84.6I) & $430(85.65)$ \\
\hline $\begin{array}{l}\text { HBV spread by casual } \\
\text { contact such as } \\
\text { handshaking }\end{array}$ & $90(82.56)$ & $83(77.57)$ & $82(79.6 I)$ & $73(79.34)$ & $62(79.48)$ & II (84.6I) & $401(79.88)$ \\
\hline $\begin{array}{l}\text { HBV spread by contact } \\
\text { with open wounds/cut? }\end{array}$ & $100(91.74)$ & $104(97.19)$ & $100(97.08)$ & 85 (92.39) & $72(92.30)$ & $12(92.30)$ & $473(94.22)$ \\
\hline $\begin{array}{l}\text { HBV can be transmitted by } \\
\text { contaminated blood and } \\
\text { body fluids }\end{array}$ & $105(96.33)$ & $104(97.19)$ & $100(97.08)$ & 85 (92.39) & $70(89.74)$ & $10(76.92)$ & 474 (94.42) \\
\hline $\begin{array}{l}\text { HBV can be transmitted by } \\
\text { unsterilized syringes, } \\
\text { needles and surgical } \\
\text { instruments }\end{array}$ & $104(95.41)$ & $100(93.45)$ & $97(94.17)$ & $84(91.30)$ & $70(89.74)$ & $9(69.23)$ & $464(92.43)$ \\
\hline $\begin{array}{l}\text { Hepatitis B transmitted by } \\
\text { unsafe sex }\end{array}$ & $100(91.74)$ & $103(96.26)$ & $85(82.52)$ & 85 (92.39) & 67 (85.89) & $10(76.92)$ & $450(89.64)$ \\
\hline $\begin{array}{l}\text { Hepatitis B transmitted } \\
\text { from mother to child }\end{array}$ & $98(89.90)$ & $102(95.32)$ & $88(85.43)$ & $82(89.13)$ & $65(83.33)$ & $9(69.23)$ & $444(88.44)$ \\
\hline $\begin{array}{l}\text { Vaccine can prevent } \\
\text { hepatitis B infection }\end{array}$ & $104(95.41)$ & $100(93.45)$ & $96(93.20)$ & $86(93.47)$ & $67(85.89)$ & $8(6 \mid .53)$ & $46 \mid(91.83)$ \\
\hline $\begin{array}{l}\text { Do you think HBV has } \\
\text { a laboratory test? }\end{array}$ & $99(90.82)$ & $92(85.98)$ & $92(89.32)$ & $75(81.52)$ & $69(88.46)$ & II (84.6I) & $438(87.25)$ \\
\hline $\begin{array}{l}\text { HBV has post exposure } \\
\text { prophylaxis }\end{array}$ & 63 (57.79) & $58(54.20)$ & $6 \mathrm{I}(59.22)$ & $43(46.73)$ & $52(66.66)$ & $8(6 \mid .53)$ & $485(56.77)$ \\
\hline $\begin{array}{l}\text { Hepatitis B can be cured/ } \\
\text { treated }\end{array}$ & 97 (88.99) & $79(73.83)$ & $80(77.66)$ & 79 (85.86) & 7I (9I.02) & $10(76.92)$ & $416(82.86)$ \\
\hline
\end{tabular}

multivariate analysis, $97.5 \%$ of the participants aged 30 34 years had good knowledge of HBV compared to $91.44 \%$ of the participants aged $25-29$ years and $92.30 \%$ of the participants aged $18-24$ years.

\section{Attitudes Towards HBV Infection and Risk Perception}

The attitudes of HCWs towards HBV infection are summarized in Table 4.

Up to $53.98 \%$ of the participants had unfavorable attitudes towards HBV infection control. Based on profession, medical doctors had the lowest favorable attitudes $(38.53 \%)$, followed by nurses $(41.74 \%)$, midwives (46.72\%), medical technologists (51.08\%), while anesthetists had the highest favorable attitudes $(61.53$ $\%$ ). Around $56 \%$ of the participants were worried about HBV infection while they were involved in HBV at work. Among them, dentists (69.23\%) were the most concerned, followed by anesthetists $(61.53 \%)$, while medical doctors $(45.87 \%)$ were the least concerned, followed by medical technologists $(52.17 \%)$. Around $69.72 \%$ of the participants had favorable attitudes 
Table 3 Multivariable Analysis of Poor Knowledge and Attitudes Towards Hepatitis B Prevention Among HCWs

\begin{tabular}{|c|c|c|c|c|c|c|}
\hline Variables & Knowledge & & P-value & Attitude & & p-value \\
\hline Profession & Good & Poor & & Favorable & Not Favorable & \\
\hline $\begin{array}{l}\text { Medical Doctors } \\
\text { Medical Technologists } \\
\text { Midwives } \\
\text { Nurses } \\
\text { Dentists } \\
\text { Anesthetist } \\
\text { Overall }\end{array}$ & $\begin{array}{l}99(90.83) \\
82(89.13) \\
104(97.20) \\
99(96.12) \\
68(87.17) \\
11(84.61) \\
463(92.23)\end{array}$ & $\begin{array}{l}10(9.18) \\
10(10.86) \\
3(2.80) \\
4(3.88) \\
10(12.82) \\
2(15.38) \\
39(7.76)\end{array}$ & 0.001922 & $\begin{array}{l}42(38.53) \\
47(51.08) \\
50(46.72) \\
43(41.74) \\
41(52.56) \\
8(61.53) \\
231(46.01)\end{array}$ & $\begin{array}{l}67(6 \mid .46) \\
45(48.91) \\
57(53.27) \\
60(58.25) \\
37(47.43) \\
5(38.46) \\
27 \mid(53.98)\end{array}$ & 0.060284 \\
\hline $\begin{array}{l}\text { Sex } \\
\text { Male } \\
\text { Female }\end{array}$ & $\begin{array}{l}223(91.02) \\
244(94.94)\end{array}$ & $\begin{array}{l}22(8.97) \\
13(5.05)\end{array}$ & 0.022069 & $\begin{array}{l}|2|(49.38) \\
|2|(47.08)\end{array}$ & $\begin{array}{l}124(50.6 I) \\
\text { I36 (52.9I) }\end{array}$ & 0.1838 \\
\hline $\begin{array}{l}\text { Age } \\
18-24 \\
25-29 \\
30-34 \\
35-39 \\
>40\end{array}$ & $\begin{array}{l}228(92.30) \\
139(91.44) \\
39(97.50) \\
36(100.00) \\
26(96.29)\end{array}$ & $\begin{array}{l}\text { I9 }(7.69) \\
\text { I3 }(8.55) \\
\text { I }(2.50) \\
0(0.00) \\
\text { I }(3.70)\end{array}$ & 0.035495 & $\begin{array}{l}107(43.31) \\
72(47.36) \\
21(52.5) \\
24(66.66) \\
18(66.66)\end{array}$ & $\begin{array}{l}140(56.68) \\
80(52.63) \\
19(47.50) \\
12(33.33) \\
9(33.33)\end{array}$ & 0.1684 \\
\hline
\end{tabular}

Table 4 Percentage of HCWs Who Responded Correctly to the Attitude Questions

\begin{tabular}{|c|c|c|c|c|c|c|c|}
\hline Knowledge Questions & $\begin{array}{l}\text { MD } \\
(n=109) \% \\
\text { of } \\
\text { Correct } \\
\text { Answer }\end{array}$ & $\begin{array}{l}\text { Midwives } \\
(n=107) \% \\
\text { of Correct } \\
\text { Answer }\end{array}$ & $\begin{array}{l}\text { Nurses } \\
(n=103) \% \\
\text { of Correct } \\
\text { Answer }\end{array}$ & $\begin{array}{l}\text { Medical } \\
\text { Technologists } \\
(n=92) \% \text { of } \\
\text { Correct } \\
\text { Answer }\end{array}$ & $\begin{array}{l}\text { Dentists } \\
(n=78) \% \text { of } \\
\text { Correct } \\
\text { Answer }\end{array}$ & $\begin{array}{l}\text { Anesthetist } \\
\text { (n-I3) \% of } \\
\text { Correct } \\
\text { Answer }\end{array}$ & $\begin{array}{l}\text { Total } \\
(n=502) \% \\
\text { of Correct } \\
\text { Answer }\end{array}$ \\
\hline $\begin{array}{l}\text { I am concerned about HBV } \\
\text { infection at work }\end{array}$ & $50(45.87)$ & $65(60.74)$ & $58(56.31)$ & $48(52.17)$ & $54(69.23)$ & $8(61.53)$ & $283(56.37)$ \\
\hline $\begin{array}{l}\text { Hepatitis B vaccine is safe } \\
\text { and effective }\end{array}$ & $87(79.81)$ & $89(83.17)$ & $36(34.95)$ & $76(82.60)$ & $53(67.94)$ & $7(53.84)$ & $348(69.72)$ \\
\hline $\begin{array}{l}\text { Changing of gloves during } \\
\text { blood collection and tests is } \\
\text { waste of time }\end{array}$ & $38(34.86)$ & 35 (32.7I) & $39(37.86)$ & $25(27.17)$ & $45(57.69)$ & $6(46.15)$ & $188(37.45)$ \\
\hline $\begin{array}{l}\text { All patients should be tested } \\
\text { for HBV before they receive } \\
\text { health care }\end{array}$ & 91 (83.48) & 93 (86.91) & $76(73.78)$ & 77 (83.69) & $60(76.92)$ & $7(53.84)$ & $404(80.47)$ \\
\hline $\begin{array}{l}\text { I do not feel comfortable to } \\
\text { take care of people with } \\
\text { HBV }\end{array}$ & $74(67.88)$ & $46(42.99)$ & 69 (66.99) & $50(54.34)$ & $37(47.43)$ & $5(38.46)$ & $28 \mathrm{I}(55.79)$ \\
\hline $\begin{array}{l}\text { Following infection control } \\
\text { guidelines will protect from } \\
\text { being infected with HBV at } \\
\text { work? }\end{array}$ & $90(82.56)$ & $90(84.11)$ & $70(67.96)$ & $74(80.43)$ & 56 (7I.79) & $4(30.76)$ & 384 (76.49) \\
\hline
\end{tabular}


towards the safety and efficacy of HBV vaccine. This percentage was highest among midwives $(83.17 \%)$, followed by medical technologists $(82.60 \%)$, and the lowest among nurses (34.95\%). Up to $37.45 \%$ of the participants thought that changing gloves during examination and blood collection was a waste of time. This percentage was highest among dentists (57.69 \%), anesthetists $(46.15 \%)$, nurses $(37.86 \%)$, and lowest among medical technologists (27.17\%). Up to $80.47 \%$ of the participants answered that before receiving healthcare, patients should be tested for HBV infection. This percentage was highest among midwives (86.91\%), followed by medical technologists ( $83.69 \%$ ), and lowest among anesthetists (53.84\%). Up to $55.79 \%$ of the participants answered that they felt uncomfortable taking care of HBV-infected patients. Among the participants, medical doctors had the highest level of discomfort in providing care for $\mathrm{HBV}$-infected patients (67.88\%), followed by nurses (66.99\%), and the lowest was among anesthetists (38.46\%), followed by midwives $(42.99 \%)$. Around $76.49 \%$ of the participants, believed that considering the guidelines for infection control will keep them safe from HBV infection at work. This belief was most common among midwives (84.11\%) and least common among anesthetists $(30.76 \%)$.

HCWs with higher levels of education showed more favorable attitudes than those with lower levels of education $(\mathrm{p}<0.0001)$. In addition, men showed more favorable attitudes than women $(p=0.18)$. According to the multivariate analysis in Tables 3, $66.66 \%$ of 35-39 years age group, $52.5 \%$ of $30-34$ years age group, $47.36 \%$ of $25-29$ years age group, and $43.31 \%$ of $18-24$ years age group showed favorable attitudes towards HBV infection control.

\section{Practices of HCWs Towards HBV Prevention}

Table 5 shows the summary of HCWs' practices towards HBV infection control.

Among participants of this study, $77.49 \%$ had been screened for HBV. The highest was among the nurses $(90.29 \%)$ and the lowest was among the anesthetists

Table 5 Percentage of Health Care Workers Who Responded Correctly to the Practice Questions

\begin{tabular}{|c|c|c|c|c|c|c|c|}
\hline \multirow[t]{2}{*}{ Practice Questions } & \multicolumn{7}{|c|}{ Profession } \\
\hline & $\begin{array}{c}\text { MD } \\
(n=109) \% \\
\text { of Correct } \\
\text { Answer }\end{array}$ & $\begin{array}{c}\text { Midwives } \\
(n=107) \% \text { of } \\
\text { Correct } \\
\text { Answer }\end{array}$ & $\begin{array}{c}\text { Nurses } \\
(n=103) \% \\
\text { of Correct } \\
\text { Answer }\end{array}$ & $\begin{array}{c}\text { Medical } \\
\text { Technologists } \\
(n=92) \% \text { of } \\
\text { Correct Answer }\end{array}$ & $\begin{array}{c}\text { Dentists } \\
(n=78) \% \text { of } \\
\text { Correct } \\
\text { Answer }\end{array}$ & $\begin{array}{c}\text { Anesthetist } \\
\text { (n-13) \% of } \\
\text { Correct } \\
\text { Answer }\end{array}$ & $\begin{array}{c}\text { Total } \\
(n=502) \% \\
\text { of Correct } \\
\text { Answer }\end{array}$ \\
\hline $\begin{array}{l}\text { Have you ever } \\
\text { screened for hepatitis } \\
\text { B? }\end{array}$ & $82(75.22)$ & $88(82.24)$ & $93(90.29)$ & $74(80.43)$ & $48(61.53)$ & $4(30.76)$ & 389 (77.49) \\
\hline $\begin{array}{l}\text { Have you got } \\
\text { vaccinated against } \\
\text { HBV? }\end{array}$ & $74(67.88)$ & $67(74.61)$ & $5 \mathrm{I}(49.5 \mathrm{I})$ & $43(46.73)$ & $47(56.4 I)$ & $4(30.76)$ & $286(56.97)$ \\
\hline \multicolumn{8}{|c|}{ How many doses of HBV vaccine did you receive? } \\
\hline Three doses & $7(6.42)$ & II (I0.28) & I (0.97) & $3(3.26)$ & II $(14.10)$ & I (7.69) & $34(6.77)$ \\
\hline $\begin{array}{l}\text { I always change gloves } \\
\text { for each patient during } \\
\text { blood taking }\end{array}$ & $89(81.65)$ & $88(89.24)$ & $85(82.52)$ & $73(79.34)$ & $55(70.5 \mathrm{I})$ & $7(53.84)$ & $397(79.08)$ \\
\hline $\begin{array}{l}\text { Have you ever had } \\
\text { a needle prick injury? }\end{array}$ & $87(79.8 I)$ & $92(87.98)$ & $88(85.43)$ & $66(71.73)$ & $60(76.92)$ & $9(69.23)$ & $402(80.07)$ \\
\hline $\begin{array}{l}\text { I always report for } \\
\text { needle stick injury }\end{array}$ & $75(68.80)$ & $76(75.02)$ & $76(73.78)$ & $65(70.65)$ & $106(57.69)$ & $10(76.92)$ & $347(69.12)$ \\
\hline
\end{tabular}


(30.76\%). Only $56.97 \%$ of the participants had been vaccinated against HBV. Only $6.77 \%$ had completed three doses, and $45.61 \%$ had received two doses of $\mathrm{HBV}$ vaccine. According to the profession, $14.10 \%$ of dentists, $10.28 \%$ of midwives, and $7.69 \%$ of anesthetists had completed the three doses of HBV vaccine, while only $0.97 \%$ of nurses had completed the three doses of HBV vaccine. Up to $79.08 \%$ of the participants stated that they always changed their gloves for each patient during blood taking. This practice was the highest among midwives $(89.24 \%)$, followed by nurses $(82.52 \%)$ and the lowest among anesthetists $(53.84 \%)$. Regarding the history of accidental exposure, $80.07 \%$ of the participants reported needle prick injury in the past. This was the highest among midwives $(87.98 \%)$ and the lowest among anesthetists (69.23\%). Only $69.12 \%$ of the participants stated that they always report needle stick injury.

\section{Discussion}

Hepatitis B is an infectious disease caused by a virus called hepatitis $B$ virus (HBV). The objectives of this study were to assess the KAP for HBV infection, awareness and uptake of HBV vaccine among HCWs in Kabul, Afghanistan.

In this study, the overall knowledge of HCWs about HBV was $86.58 \%$, which was similar to the study in Nigeria $(86.30 \%),{ }^{17}$ and higher than the study in Ethiopia $(73.10 \%) .{ }^{18}$ Most of the participants were aware that HBV could be infected by unsterile syringes, needles, and surgical instruments $(92.43 \%)$, by contaminated blood and body fluids $(94.42 \%)$, by contact with open wounds and cuts $(94.22 \%)$, by unsafe sex $(89.64 \%)$, and by mother-to-child transmission (88.44\%). This is almost similar to a study in Ethiopia in which $92.9 \%$ of the participants answered infected blood, and approximately $88 \%$ answered vaginal fluid or amniotic fluid as routes of infection. ${ }^{18}$ In Nigeria, more than $80 \%$ of the participants reported that the routes of HBV infection were percutaneous injury, contact with mucosal membranes and blood, and contact with scratched skin and potentially infected tissue. ${ }^{19}$

Regarding the perception of HBV vaccine, $69.72 \%$ of HCWs perceived HBV vaccine to be safe and effective, which is much lower than the results of other similar studies. In addition, participants in Kuwait (86.3\%), Cameron (93 $\%$ ), Nigeria (94\%), and Ethiopia (94\%) felt that vaccination was necessary and should be mandatory. ${ }^{11,18,20}$

Up to $53.98 \%$ of the participants had unfavorable attitudes towards HBV vaccination, and only $56.37 \%$ of
$\mathrm{HCW}$ sere worried about getting infected with HBV, which is different from other similar studies. Participants in Kuwait (80.50\%), Cameron (96.00\%), and Ethiopia $(91.3 \%)$ believed that their job put them at risk of HBV infection, ${ }^{11,18,20}$ and participants in Nigeria (92.7\%) recognized that they were at higher risk of $\mathrm{HBV}$ infection compared to the general population. ${ }^{17}$

Up to $80.47 \%$ of HCWs agreed that all patients should be tested for HBV before receiving healthcare. This belief was at the highest among midwives (86.91\%), followed by medical technologists (83.69\%), and at the lowest among anesthetists (53.84\%). Up to $79.08 \%$ of the participants answered that they constantly changed their gloves for each patient during blood taking. This percentage was highest among midwives $(89.24 \%)$ and lowest among anesthetists (53.84\%).

Regarding the history of accidental exposure, $80.07 \%$ of the participants reported needle prick injury in the past, which is much higher than in similar studies. In Ethiopia, $49.20 \%$ of the participants reported that they had been exposed to risky situations of HBV infection. ${ }^{18}$ This study found that $56.37 \%$ of the participants had been vaccinated against HBV, which is higher than results from Japan $(48.20 \%),{ }^{21}$ and from Nigeria $(40.30 \%) .{ }^{17}$ Among these HCWs, only $6.77 \%$ had completed the three doses of vaccination. This is a much lower percentage than in other studies. In Nigeria, $56.0 \%$ of the participants who had been vaccinated against HBV infection had received the recommended three doses of vaccination. ${ }^{17}$

\section{Conclusion}

The results of this study revealed that the overall knowledge of $\mathrm{HBV}$, its routes of infection, and prophylaxis was high $(86.58 \%)$. In addition, among the HCWs, the group with higher education levels had better knowledge than the group with lower education level. Medical doctors showed better knowledge than other professionals, and women showed better levels of knowledge than men. This study also revealed that the majority of HCWs have unfavorable attitude towards HBV prevention. Furthermore, attitude changed depending on the healthcare profession. Medical doctors had the lowest favorable attitude, followed by nurses, midwives. In this study, HBV prophylaxis among $\mathrm{HCW}$ s in Kabul was inadequate, and vaccination coverage was very low, with only $6.77 \%$ of participants having completed three doses of vaccination. The solution for this issue is to encourage HCWs to take the HBV vaccine and complete the required doses and provide the vaccine for free and make it mandatory. Furthermore, it is 
necessary to implement enlightenment programs to improve the importance and favoritism of preventive measures and practices against HBV among HCWs.

\section{Ethical Approval}

Ethics approval for conducting study was approved by Kateb University's Human Research Ethics Committee (Approval numbers: AF.KU. HREC040.03/02/2018). All participants provided informed consent, in accordance with the Declaration of Helsinki.

\section{Acknowledgment}

The authors would like to acknowledge Yudai Kaneda (School of Medicine, Hokkaido University, Sapporo, Hokkaido, Japan) for proofreading and suggestions.

\section{Author Contributions}

All authors made a significant contribution to the work reported, whether that is in the conception, study design, execution, acquisition of data, analysis, and interpretation, or in all these areas; took part in drafting, revising, or critically reviewing the article; gave final approval of the version to be published; have agreed on the journal to which the article has been submitted; and agree to be accountable for all aspects of the work.

\section{Disclosure}

Dr Akihiko Ozaki report personal fees from MNES Inc, outside the submitted work. The authors report no other conflicts of interest in this work.

\section{References}

1. World Health Organization. Hepatitis B. Available from: https://www.who. int/news-room/fact-sheets/detail/hepatitis-b. Accessed August 14, 2021.

2. World Health Organization. Global hepatitis report, 2017. Available from: https://www.who.int/publications/i/item/global-hepatitis-report -2017. Accessed August 14, 2021.

3. Auta A, Adewuyi EO, Kureh GT, Onoviran N, Adeloye D. Hepatitis $B$ vaccination coverage among health-care workers in Africa: a systematic review and meta-analysis. Vaccine. 2018;36 (32):4851-4860. doi:10.1016/j.vaccine.2018.06.043

4. World Health Organization. Hepatitis B vaccines: WHO position paper, July 2017 - recommendations. Vaccine. 2019;37(2):223-225. doi:10.1016/J.VACCINE.2017.07.046.

5. Yuan Q, Wang F, Zheng $\mathrm{H}$, et al. Hepatitis B vaccination coverage among health care workers in China. PLoS One. 2019;14(5):e0216598. doi:10.1371/JOURNAL.PONE.0216598

6. Rapiti E, Prüss-üstün A, Hutin YJF. Sharps injuries: assessing the burden of disease from sharps injuries to health-care workers at national and local levels/Elisabetta Rapiti, Annette Prüss-Üstun, Yvan Hutin; 2005. Available from: https://apps.who.int/iris/handle/ 10665/43051. Accessed November 2, 2021.
7. Malewezi B, Omer SB, Mwagomba B, Araru T. Protecting health workers from nosocomial Hepatitis B infections: a review of strategies and challenges for implementation of Hepatitis B vaccination among health workers in Sub-Saharan Africa. J Epidemiol Glob Health. 2016;6(4):229-241. doi:10.1016/j.jegh.2016.04.003

8. Wondimeneh Y, Alem M, Asfaw F, et al. HBV and HCV seroprevalence and their correlation with CD4 cells and liver enzymes among HIV positive individuals at University of Gondar Teaching Hospital, Northwest Ethiopia. Virol J. 2013;10:171. doi:10.1186/1743-422X$10-171$

9. Geberemicheal A, Gelaw A, Moges F, Dagnaw M. Seroprevalence of hepatitis B virus infections among health care workers at the Bulle Hora Woreda Governmental Health Institutions, Southern Oromia, Ethiopia. $J$ Environ Occup Sci. 2013;2(1):9. doi:10.5455/ jeos.20130220105759

10. Anagaw B, Shiferaw Y, Anagaw B, et al. Seroprevalence of hepatitis $\mathrm{B}$ and $\mathrm{C}$ viruses among medical waste handlers at Gondar town Health institutions, Northwest Ethiopia. BMC Res Notes. 2012;5:55. doi:10.1186/1756-0500-5-55

11. Tatsilong HOP, Noubiap JJN, Nansseu JRN, et al. Hepatitis $\mathrm{B}$ infection awareness, vaccine perceptions and uptake, and serological profile of a group of health care workers in Yaoundé, Cameroon. BMC Public Health. 2016;16(1):1-7. doi:10.1186/ S12889-016-3388-Z

12. Molinari JA. Infection control: its evolution to the current standard precautions. J Am Dent Assoc. 2003;134(5):569-632. doi:10.14219/ jada.archive.2003.0222

13. West DJ. The risk of hepatitis B infection among health professionals in the United States: a review. Am J Med Sci. 1984;287(2):26-33. doi:10.1097/00000441-198403000-00006

14. Khan S, Attaullah S. Share of Afghanistan populace in hepatitis B and hepatitis C infection's pool: is it worthwhile? Virol J. 2011;8:216. doi:10.1186/1743-422X-8-216

15. Behzadi MA, Ziyaeyan M, Asaei S. Hepatitis B virus DNA level among the seropositive Afghan immigrants, Southern Iran. Jundishapur J Microbiol. 2014;7(5):e10127. doi:10.5812/jjm.10127

16. Abdela A, Woldu B, Haile K, Mathewos B, Deressa T. Assessment of knowledge, attitudes and practices toward prevention of hepatitis $B$ virus infection among students of medicine and health sciences in Northwest Ethiopia. BMC Res Notes. 2016;9(1). doi:10.1186/ S13104-016-2216-Y

17. Hassan M, Awosan KJ, Nasir S, et al. Knowledge, risk perception and hepatitis B vaccination status of health-care workers in Usmanu Danfodiyo University Teaching Hospital, Sokoto, Nigeria. J Public Health Epidemiol. 2016;8(4):53-59. doi:10.5897/JPHE2015.0795

18. Ayalew MB, Horssa BA, Getachew N, Amare S, Getnet A. Knowledge and attitude of health care professionals regarding hepatitis B virus infection and its vaccination, University of Gondar Hospital, Ethiopia. Hepat Med. 2016;8:135. doi:10.2147/HMER. S120477

19. Kesieme EB, Uwakwe K, Irekpita E, Dongo A, Bwala KJ, Alegbeleye BJ. Knowledge of Hepatitis B vaccine among operating room personnel in Nigeria and their vaccination status. Hepat Res Treat. 2011;2011:157089. doi:10.1155/2011/157089

20. Habiba SA, Alrashidi GA, Al-otaibi AEM, Almutairi GR, Makboul G, El-Shazly MK. Knowledge, attitude and behavior of health care workers regarding hepatitis B infection in primary health care, Kuwait. Greener J Med Sci. 2012;2(4):077-083. doi:10.15580/ GJMS.2012.4.GJMS1221

21. Nagao Y, Matsuoka H, Kawaguchi T, Ide T, Sata M. HBV and HCV infection in Japanese dental care workers. Int J Mol Med. 2008;21 (6):791-799. doi:10.3892/IJMM.21.6.791 


\section{Publish your work in this journal}

The Journal of Multidisciplinary Healthcare is an international, peerreviewed open-access journal that aims to represent and publish research in healthcare areas delivered by practitioners of different disciplines. This includes studies and reviews conducted by multidisciplinary teams as well as research which evaluates the results or conduct of such teams or healthcare processes in general. The journal covers a very wide range of areas and welcomes submissions from practitioners at all levels, from all over the world. The manuscript management system is completely online and includes a very quick and fair peer-review system. Visit http://www.dovepress.com/testimonials. php to read real quotes from published authors. 